\title{
A retrospective controlled study comparing Spinecor vs exercises for Adolescent Idiopathic Scoliosis
}

\author{
Fabio Zaina*, Fabio Digiacomo, Fabio Zaina, Michele Romano, Alessandra Negrini, Sabrina Donzelli, Monia Lusini, \\ Salvatore Minnella, Stefano Negrini
}

From 10th International Conference on Conservative Management of Spinal Deformities - SOSORT 2013

Annual Meeting

Chicago, IL, USA. 8-11 May 2013

\section{Background}

SpineCor and exercises both have results testifying to their effectiveness in Adolescent Idiopathic Scoliosis (AIS) treatment. Several years ago, we introduced SpineCor as a treatment for patients at the highest risk of bracing which we previously treated with exercises. In a previous study, we compared the short-time results of SpineCor and specific exercise for AIS.

\section{Purpose}

The objective of this study was to compare the end treatment results of the SpineCor vs. Scientific Exercises Approach to Scoliosis (SEAS) for AIS.

\section{Methods}

Study design: retrospective controlled study. Population: Exercise Group (EG): 28 consecutive scoliosis patients (26 females), age $13 \pm 2$, TRACE 4.5 , Cobb angle $18 \pm 3^{\circ}$, ATR $7 \pm 3^{\circ}$, Risset 0 - 3 .

SpineCor Group (SG): 41 patients (33 females), age 13 \pm 1 , TRACE score 6 , Cobb angle $24 \pm 5^{\circ}$; ATR $8 \pm 3^{\circ}$, Risser 0-3. EG patients performed specific exercises twice per week according to the SEAS protocol. SG patients wore the SpineCor brace 20 hours per day. Patients were evaluated both clinically and radiographically before and after the treatment. Main outcome measured TRACE (changes $\geq 3$ ), Cobb angle (changes $> \pm 5$ ) and ATR.

\section{Results}

At baseline, the Cobb angle in the SG was significantly larger than the EG group. Considering the number of patients with significant changes for Cobb angle, we found $7 \%$ improved, $36 \%$ stable and $57 \%$ worsened vs. $22 \%, 32 \%$ and $46 \%$ respectively ( $p>0.05$ ). For ATR, the results were similar. There were similar results for TRACE: $46 \%$ improved and 54\% stable for EG versus $65 \%, 31 \%$ and $4 \%$ worsened in the SG $(\mathrm{P}>0.05)$.

\section{Conclusions and discussion}

There was a slight difference among groups at the beginning of the study, so the interpretation of the results must be cautious. Both treatments could achieve some improvements of the aesthetics. In terms of risk of progression, results were slightly better for SpineCor, but the difference is not statistically significant. This could be due to the difference in the initial Cobb angle: the SpineCor group included more severe curves compared to the exercise group. The main limits of the study were the retrospective design and the small population. Moreover, the initial difference in the severity of the curve made the comparison not totally reliable.

\section{Published: 18 September 2013}

\section{References}

1. Zaina F, Donzelli S, Negrini A, Romano M, Negrini S: SpineCor, exercise and SPoRT rigid brace: what is the best for Adolescent Idiopathic Scoliosis? Short term results from 2 retrospective studies. Stud Health Technol Inform 2012, 176:361-4.

2. Negrini S, Zaina F, Romano M, Negrini A, Parzini S: Specific exercises reduce brace prescription in adolescent idiopathic scoliosis: a prospective controlled cohort study with worst-case analysis. J Rehabil Med 2008, 40(6):451-5, doi: 10.2340/16501977-0195.

* Correspondence: fabio.zaina@isico.it

ISICO Italian Scientific Spine Institute, Milan, Italy

(c) 2013 Zaina et al; licensee BioMed Central Ltd. This is an Open Access article distributed under the terms of the Creative Commons 
3. Negrini S, Aulisa AG, Aulisa L, Circo AB, de Mauroy JC, Durmala J, et al: 2011 SOSORT guidelines: Orthopaedic and Rehabilitation treatment of idiopathic scoliosis during growth. Scoliosis 2012, 7(1):3.

doi:10.1186/1748-7161-8-S2-057

Cite this article as: Zaina et al:: A retrospective controlled study

comparing Spinecor vs exercises for Adolescent Idiopathic Scoliosis.

Scoliosis 2013 8(Suppl 2):057.

Submit your next manuscript to BioMed Central and take full advantage of:

- Convenient online submission

- Thorough peer review

- No space constraints or color figure charges

- Immediate publication on acceptance

- Inclusion in PubMed, CAS, Scopus and Google Scholar

- Research which is freely available for redistribution

Submit your manuscript at www.biomedcentral.com/submit 